\title{
DOSSIÊ TEMÁTICO CABOCLO: APRESENTAÇÃO ${ }^{1}$
}

CABOCLO: A PRESENTATION

\author{
Clara Flaksman ${ }^{2}$ \\ Miriam C. M. Rabelo
}

"Caboclo" é um termo com uma ampla variedade de significados. Inicialmente, podemos traçar a distinção mais evidente: refere-se tanto a pessoas quanto a entidades espirituais ${ }^{4}$. Este dossiê se refere especificamente ao universo das entidades denominadas "caboclos". Mas não só isso: conta também com um recorte geográfico, pois trata do universo dos caboclos em uma área determinada, a saber, o estado da Bahia (com a exceçáo de um dos artigos que se estende à fronteira entre Bahia e Pernambuco). Assim, apesar dos caboclos e caboclas estarem presentes em quase todas as regiôes do Brasil (na encantaria amazônica, por exemplo), os artigos aqui apresentados se concentram nessa área específica, com suas características distintivas e particularidades.

De forma geral, como pensamos que ficará evidente para o leitor dos artigos que seguem, podemos dizer - ainda que pareça paradoxal - que a

${ }^{1}$ Como citar: FLAKSMAN, C. RABELO, M. C. M. Dossiê temático caboclo: apresentação. Debates do NER, Porto Alegre, v. 2, n. 38, p. 137 - 143, 2020.

2 Doutora em Antropologia Social pela Universidade Federal do Rio de Janeiro, Brasil. Atualmente realiza pós-doutorado (Faperj) no Programa de Pós-Graduação em Antropologia Social do Museu Nacional/Universidade Federal do Rio de Janeiro, Brasil. E-mail: claramflaksman@gmail.com.

${ }^{3}$ Doutora em Ciências Sociaia/Antropologia pela University of Liverpool, LIVERPOOL, Inglaterra. Atualmente é professora titular do Departamento de Sociologia e do Programa de Pós-Graduação em Ciências Sociais da Universidade Federal da Bahia, Brasil. E-mail: mcmrabelo@uol.com.br.

${ }^{4}$ Dentro dessa primeira variação, há outras diferenciaçôes, referentes aos tipos de seres (tanto pessoas quanto entidades) que são denominados "caboclos". 
principal dessas particularidades, ou seja, o traço comum a todos os caboclos que aqui aparecem, é a sua variação. O que parece claro, ao se ler os artigos reunidos em conjunto, é que o caboclo, enquanto entidade, não se presta a essencializaçóes. Abdicando de defini-los por meio de categorias prévias os textos optam por apresentar os caboclos a partir de seu movimento ou das histórias, pessoas e territórios que, ao chegar, eles póem em movimento. $\mathrm{O}$ espaço surge assim como dimensão essencial para se entender como as relações com essas entidades se constroem nas vidas daqueles e daquelas que com elas se relacionam. Mas trata-se de um espaço móvel: que junta e condensa tempos e lugares diferentes e que é feito, de maneira situada, por afinidades e afetos.

Dessa forma, a proposta do dossiê é reunir trabalhos que, apoiados na etnografia, possam abrir novos caminhos para o entendimento dos caboclos e seus efeitos nos terreiros, nas comunidades e na vida das pessoas que são tocadas por eles. Ao compor um pequeno corpus etnográfico sobre os caboclos, o dossiê objetiva menos oferecer análises definitivas acerca dessas entidades, do que alargar os modos e perspectivas de acompanhá-las em seu movimento.

Este dossiê tem sua origem em um projeto de pesquisa iniciado em 2017, no Programa de Pós-Graduação em Ciências Sociais da Universidade Federal da Bahia (PPGCS/UFBA), sob nossa coordenação. Intitulada "Caminhos e Moradas dos Caboclos na Bahia", a pesquisa tem como objetivo mapear o que denominamos "rota dos caboclos": um percurso em que encontramos o registro de formas religiosas em que os caboclos se destacam.

Procuramos, assim, tanto o "candomblé de caboclo" propriamente dito quanto terreiros onde os caboclos são os elementos principais do culto. Porém, mais do que desvendar a 'origem' do caboclo, o projeto pretende traçar os seus caminhos. Baseando-se na concepção específica de caminho no candomblé baiano (tanto trajetória percorrida quanto destino), busca 
reconstruir trajetórias que permitam entender os caminhos dos caboclos e seus efeitos nas dinâmicas dos territórios, terreiros e famílias por onde passam. A reconstrução narrativa dos cultos, incluindo aí os fluxos biográficos tanto das entidades quanto de seus médiuns, assume papel central na pesquisa. Ao empreendermos essa reconstrução, entretanto, abandonamos um modelo cronológico linear em favor de uma abordagem atenta aos múltiplos planos, temporais e espaciais, que são conectados pelo movimento dos caboclos.

Embora o dossiê não seja resultado de uma pesquisa comum ou de um encontro prévio entre os autores, a reuniáo dos artigos seguiu dois critérios básicos. O primeiro, como já foi dito, foi geográfico: buscamos trabalhos que tratassem dos caboclos na Bahia (o trabalho de Marcia Nóbrega é o que amplia um pouco a área coberta, ao se localizar na Ilha do Massangano, no Rio São Francisco, entre Juazeiro e Petrolina). Seguimos, assim, no objetivo da pesquisa que nos trouxe originalmente até aqui.

A decisão de fazer tal seleção não é aleatória: decorre de uma reflexão sobre a maneira como os caboclos se relacionam com o território, o que nos leva a um tema abordado em quase todos os artigos: o fato de o caboclo ser considerado, especialmente na Bahia, o "dono da terra". Denominação que enseja diversos tipos de reflexão, como os leitores verão, o título de "dono da terra", neste caso, diz menos respeito à ideia de propriedade do que a uma relação específica com o território e com as formas de vida que nele habitam.

O segundo critério, de que já falamos, diz respeito à abordagem utilizada: todos os textos têm um caráter etnográfico. $\mathrm{O}$ foco, em todos, está nas descriçôes etnográficas dos caboclos, tanto daquilo que eles fazem quanto daquilo que eles "fazem fazer". Os caboclos, assim, aparecem como mediadores: carregam a informação, transformando-a, ao mesmo tempo em que, com seu movimento, formam a rede que permite que a descrição seja feita.

Por fim, vale notar que todos os textos compartilham um léxico que, ao longo do conjunto de artigos, vai se mostrando cada vez mais comum. 
Assim, ao longo da leitura, podemos notar a repetiçáo de termos como caminho, mistura, linha, corrente, terra. Termos que, acreditamos, cada vez mais tendem a ser incorporados às etnografias que tratem dos caboclos e de seus movimentos.

O primeiro artigo do dossiê, "Na rota dos caboclos", assinado por nós duas conjuntamente, é resultado direto da pesquisa referida acima. Acompanha o movimento dos caboclos e com eles transita entre o Recôncavo Baiano e a Chapada Diamantina. No texto buscamos justamente explorar os efeitos de uma perspectiva que valoriza o movimento enquanto modo de existir dos caboclos para tratar das formas de convivência e "mistura" que essas entidades promovem e dos tipos de espaço que ajudam a construir ao trazer seus territórios de mata, água e sertão.

Marcia Nóbrega, em seu artigo, ilustra a dificuldade de essencialização do caboclo, quando conversa com uma amiga da Ilha do Massangano, que frente à sua busca de uma definição para essa entidade, lhe responde com a seguinte assertiva: "caboclo é tudo". Mas não só isso. Nóbrega mostra como a relaçáo que os moradores da Ilha do Massangano estabelecem com os caboclos é pensada a partir da maneira como eles compóem suas vidas com as correntes de água que os cercam. Os caboclos são correntes e partes das correntes: todo e parte ao mesmo tempo, compóem com as forças e com as pessoas da Ilha, criando um parentesco que se dá tanto pela territorialidade quanto pelo "caminhar junto".

Com o artigo de Nóbrega compreendemos como, para os habitantes da Ilha do Massangano, o movimento dos caboclos está justamente ligado à sua potência vital tanto em escala micro quanto macroscópica. Pois a autora nos mostra que o perigo iminente do fim do mundo, para eles, está ligado justamente à possibilidade da terra tornar-se estática. Se a terra perder o seu movimento, ou seja, perder as variaçôes que, afinal, a fazem ser ilha, pode juntar-se definitivamente à terra firme e "acabar".

Debates do NER, Porto Alegre, ano 20, N. 38, P. I 37-I 43, Ago./Dez. 2020 
Já Carolina Pedreira, a partir de sua experiência com o jarê da Chapada Diamantina - onde, em uma analogia com a Ilha do Massangano, "tudo é caboclo" -- analisa essa entidade a partir da experiência da irradiaçáo (ou, no linguajar local, "radiação"), uma de suas manifestaçóes possíveis.

A irradiação, para Pedreira, é um modo de ser com os caboclos: tanto um modo de se compor com eles quanto um marcador da boa distância que se deve manter deles para que a vida transcorra da melhor maneira possível. Pedreira pensa, assim, não somente os encontros entre as pessoas e os caboclos, mas entre os caboclos e as outras entidades que acompanham as pessoas - especialmente as "almas". O que ela aponta, justamente, é que a manutenção da distância que assegura a convivência entre pessoas, almas e caboclos requer que seus encontros sejam mediados. Importantes agentes nesse processo de composiçáo, os caboclos frequentemente atuam como mediadores que mantém aberta a possibilidade de entidades diferentes viverem juntas. Em seu texto, Pedreira propóe que pensemos as relaçóes entre caboclos, pessoas e "almas" sob a chave da irradiação. Que, segundo ela, é "um jeito de sambar. E sambar é um jeito de viver junto com caboclos e, assim, de aprender a ser com eles e de zelar do que se é" (p. 20).

E é justamente o samba dos caboclos o assunto do artigo de Ana Sheldon, onde este aparece conectado aos muitos modos dessas entidades se moverem nas celebraçóes públicas do candomblé de Salvador. Embora trate da dança, o objetivo de Sheldon não é construir um inventário dos gestos e passos característicos dos caboclos. Tal estratégia teria como consequência justamente congelar o movimento e tornar invisível sua criatividade fundamental - algo ainda mais problemático quando se trata de falar do movimento de entidades que primam não só por sua liberdade, como também por sua capacidade de tecer relaçóes e responder aos convites que lhe sáo feitos para se conectar. Assim, Sheldon opta por descrever o movimento dos caboclos enquanto parte de processos de articulação envolvendo entidades, pessoas (filhos de santo e plateia) e substâncias diversas, articulaçóes que ecoam para além do espaço da festa, atravessando territórios e geraçóes. Acompanhando a movimentação do caboclo Lage Mineiro, o texto oferece um quadro móvel 
(e, portanto, vivo) das muitas linhas de conexão que os caboclos produzem e nas quais se enredam.

Em seu artigo "É daquele que vem da mata e dá uns pulos": o movimento do caboclo na vida e na escrita, Maíra Vale sugere a possibilidade de compor uma narrativa que seja plural como o caboclo e que, como ele, se movimente, não permanecendo estática e/ou atada a prerrogativas que não lhe fariam justiça. Vale sugere deixar que o texto se contamine pela presença dos caboclos (e de outras entidades) e que eles possam, assim, conduzir a narrativa de forma a buscar uma linguagem que permita a ela descrever a sua experiência sem enquadrá-la analiticamente (p. 20/21), "imprimindo na escrita uma forma de viver" (p. 21). Só assim, ela argumenta, poderia fazer justiça a suas experiências com os caboclos, já que, em Cachoeira, os candomblés se 'espalham' pelas ruas, não estando limitados somente aos terreiros ou outros espaços classificados previamente como 'sagrados'.

É intercalando trechos da bibliografia sobre a participação do caboclo nos candomblés da Bahia com partes de sua etnografia, narrada com a delicadeza de um texto 'contaminado' pela presença das entidades cachoeiranas, que Vale conta o encontro entre negros e indígenas no Recôncavo Baiano, tema retomado pelo artigo subsequente.

$\mathrm{O}$ artigo que fecha este dossiê, assinado por Marinho Rodrigues e Marcio Goldman, é elaborado a partir de imagens obtidas em uma festa em homenagem aos caboclos, em 1989. Nele, há uma revisão da chegada dos caboclos ao candomblé, da aliança que se fez entre os africanos e africanas trazidos à força para o Brasil e os indígenas que já habitavam esta terra. Através da história do terreiro Matamba Tombenci Neto e dos caboclos de Dona Ilza, a atual mãe de santo, e dos outros que a antecederam, assim como de citaçóes da própria e de outros grandes nomes do candomblé que falaram sobre o tema, os autores contam a história dos candomblés de caboclo no Brasil.

$\mathrm{O}$ artigo de Rodrigues e Goldman trata diretamente de um tema que atravessa todos os outros textos. Assim como o movimento é a diretriz presente em todos os artigos, o artigo de Goldman e Rodrigues traz também 
à baila o tema da mistura. Porém, o que fica claro no artigo é que não se trata de uma mistura que resulte em uma fusão. Trata-se, antes, da construção de um meio ou, antes, de um território, para que as práticas de negros e indígenas se encontrassem sem que houvesse a necessidade de que ambas se tornassem uma só, ou de que uma eclipsasse a outra.

Esperamos que, ao longo da leitura dos artigos, o leitor possa ter uma mirada, ainda que breve, sobre o amplo universo dos caboclos da Bahia, composto tanto pela própria entidade como por tudo aquilo que ela coloca em conexão.

Recebido em: 07/08/2020

Aprovado em: 07/08/2020

Debates do NER, Porto Alegre, ANo 20, N. 38, P. I 37-I 43, Ago./Dez. 2020 
